\title{
A importância da gestão escolar em projetos de ensino: a busca por mudanças em paradigmas socioambientais
}

Gestão e Educação Ambiental. Surge a necessidade de trabalhar nas escolas para além das salas de aula. Devem-se buscar mudanças de paradigmas socioambientais e socioculturais. Educação Ambiental deve ser trabalhada e discutida, apresentando de forma prática aos estudantes. Buscando resolver pequenas situações-problemas locais, mas, sem esquecer que também podem colaborar para amenizar problemas mais abrangentes. É defendida na Lei 9.795/99. Tendo o enfoque a valorização da vida humana e da biodiversidade. É através da educação ambiental que se podem conscientizar os estudantes da atual situação em que se encontra o planeta, sabendo que a espécie 'Sapiens' que é a grande responsável por esta situação, onde está ficando impossível a existência de muitas espécies. Por isso é primordial conscientizar e sensibilizar a comunidade escolar para os avanços escolares sem perder o foco numa Educação transformadora que leve todos a se posicionarem e a buscar melhorias nos campos socioculturais, socioambientais e socioeconômicos de forma sustentável. E que novas atitudes necessitam ser tomadas antes que o pior aconteça. Esta temática é universal todos devem reconhecer que podem ajudar de alguma forma. 0 estudo da educação ambiental não pode ser algo engessado como tem sido, mas de uma forma prática e objetiva. O presente artigo busca responder qual é a importância da gestão escolar nos projetos de ensino para mudanças de paradigmas socioambientais.

Palavras-chave: Currículo; Paradigmas; Educação; Sustentabilidade; Ensino-aprendizagem.

\section{The importance of supporting school management in teaching projects: the search for changes in socio-environmental paradigms}

\begin{abstract}
Environmental Management and Education. There is an urgent need to work in schools beyond classrooms. Changes in socioenvironmental and sociocultural paradigms should be sought. Environmental education should be worked and discussed, presenting to students in a practical way. Seeking to solve small local problem situations, but without forgetting that they can also help to alleviate broader problems. It is defended in Law 9.795/99. Focusing on valuing human life and biodiversity. It is through environmental education that students can be made aware of the current situation of the planet, knowing that the species 'Sapiens' is largely responsible for this situation, where it is becoming impossible for many species to exist. That is why it is essential to raise awareness and make the schoo community aware of school progress without losing focus on a transformative education that leads everyone to position themselves and seek improvements in the socio-cultural, socio-environmental and socioeconomic fields in a sustainable manner. And what new attitudes need to be taken before the worst happens. This theme is universal everyone should recognize that they can help in some way. The study of environmental education cannot be as plastered as it has been but in a practical and objective way.
\end{abstract}

Keywords: Curriculum; Paradigms; Education; Sustainability; Teaching-learning.

Topic: Gestão e Empreendedorismo no Campo Educacional

Reviewed anonymously in the process of blind peer
Received: $\mathbf{2 4 / 1 0 / 2 0 2 0}$

Approved: 25/01/2021
Jailson Mauricio Pinto (D)

Universidade Federal do Espírito Santo, Brasil

http://lattes.cnpq.br/5630364581431753

http://orcid.org/0000-0002-4051-0051

jailsonecop@hotmail.com

Ivani Vieira Damaceno (iD)

Universidade Federal do Espírito Santo, Brasil

http://lattes.cnpq.br/7230901191155082

http://orcid.org/0000-0002-7140-7241

ivanivida@gmail.com

Douglas Vicente do Carmo Lima

Universidade Federal do Espírito Santo, Brasi

http://lattes.cnpq.br/8496236068852285

biologia14vicente@gmail.com
Referencing this:

PINTO, J. M.; DAMACENO, I. V.; LIMA, D. V. C.. A importância da gestão escolar em projetos de ensino: a busca por mudanças em paradigmas socioambientais. Educationis, v.9, n.1, p.17-29, 2021. DOI: http://doi.org/10.6008/CBPC2318-3047.2021.001.0003 


\section{INTRODUÇÃO}

Educação Ambiental, tema de extrema relevância e abrangente para ser discutido e trabalhado nas escolas e nos demais segmentos da sociedade. Há uma necessidade conscientizar pais, estudantes e comunidade em geral como está à situação em relação à devastação do meio ambiente e que o principal causador deste feito são os seres que se sentem 'superiores' aos demais seres vivos: os seres humanos.

Em função de tudo isso, a Educação Ambiental tem o importante papel de fomentar a percepção da necessidade de interação com o meio ambiente. Sabendo que deve ser uma relação harmoniosa, consciente do equilíbrio dinâmico na natureza, possibilitando, por meio de novos conhecimentos, valores e atitudes de inserção do educando e do educador no processo de transformação do quadro ambiental em que se encontra nosso planeta.

A educação ambiental é uma temática que deve ser incluída no projeto político pedagógico da escola. E que todos da comunidade escolar devem ajudar a desenvolver. Além disso, a escola ao trabalhar a educação ambiental deve buscar parcerias com outras entidades para que o seu trabalho possa surgir efeito. Lima (1984, citado por GUIMARÃES, 1995), onde diz:

(...) a educação ambiental exige uma postura crítica e um corpo de conhecimento produzido a partir de uma reflexão sobre a realidade vivenciada. Sendo uma proposta essencialmente comunitária, materializa-se através de uma prática cujo objetivo maior é a promoção de um comportamento adequado à proteção ambiental. Comporta uma concepção desalienante, porquanto pressupõe ações voltadas para o surgimento de novos valores, onde a participação é um princípio fundamental.

Além da parte teórica não podemos esquecer que educação ambiental sem prática não existe. Porque todos nós sabemos dos problemas existentes no meio ambiente. Por isso temos que aplicar educação ambiental teórica e prática, para que possamos ver o surgimento de um mundo ético, de qualidade, com práticas cidadãs indispensáveis à democracia e à emancipação socioambiental, protegendo a biodiversidade de nosso planeta.

Mesmo sabendo que o ser humano, é parte integrante da natureza, não há um consenso sobre as práticas de educação ambiental e muitas vezes as práticas de gestão e educação ambiental não são realizadas com Êxito. Existe muita fala e pouca ação. Percebe-se que mesmo com tantas Leis Ambientais que o Brasil possui em todas as esferas da Federação, muitas vezes as mesmas são ineficientes para diminuir a destruição dos recursos naturais. O ser humano, sendo a espécie 'Sapiens' está se autodestruindo e consigo todas as outras espécies, além dos recursos naturais. Esta autodestruição está levando o planeta a uma crise mundial. Capra (1989, citado por GUIMARÃES, 1995), que diz:

As últimas duas décadas de nosso século vêm registrando um estado de profunda crise mundial. É uma crise complexa, multidimensional, cujas facetas afetam todos os aspectos. De nossa vida a saúde e o modo de vida, a qualidade do meio ambiente e das relações sociais, da economia, tecnologia e política. É uma crise de dimensões intelectuais, morais e espirituais; uma crise de escala e premência sem precedentes em toda a história da humanidade. Pela primeira vez, temos que nos defrontar com a real ameaça de extinção da raça humana e toda a vida no planeta.

Guimarães (1995), também nos fala: 
Qual a separação que existe entre o ser humano e o meio ambiente, se a todo o momento o ser humano aspira para o seu interior o ar que circunda ingere a água que bebe, o alimento que come, exterioriza e interioriza sentimentos para com outra pessoa, uma flor, um animal, uma paisagem? Uma relação intrínseca e vital com o ambiente.

Confirma-se assim na Educação Ambiental um conhecido lema ecológico, o agir localmente, pensando globalmente. Sabendo que pensar e agir deverão estar interligados para que as ações planejadas sejam executadas.

É sabida a importância de todos cuidarem do Ambiente. Por isso metas devem ser traçadas para que ações corriqueiras que há décadas vem sendo realizadas pelos moradores do Distrito de Imburana, bem como toda a comunidade escolar em relação ao descaso com os recursos naturais que temos, bem como propor estratégias que melhorem tanto o rendimento dos estudantes por meio de projetos de ensino que valorizem a vida estudantil no processo ensino-aprendizagem e as práticas de educação ambiental de acordo com as vivencias dos estudantes.

\section{DISCUSSÃO TEÓRICA}

\section{Caracterização do distrito estudado}

A pesquisa que culminou nesse artigo, foi realizada no Distrito de Imburana, um dos sete Distritos da cidade de Ecoporanga-ES, O Distrito foi criado pela Lei Estadual no 3.046, de 14 de maio de 1976. Fica aproximadamente a 208 metros de altitude, a uma distância de $19 \mathrm{~km}$ da sede. $O$ distrito tem uma população de aproximadamente de 1.200 habitantes. Segundo relatos de moradores antigos da região, a origem do nome é devido à grande quantidade da árvore Imburana (Commiphora leptophloeos), que ocorria na localidade, uma espécie da flora Brasileira, característica da vegetação de Caatinga, que apresenta portes variáveis conforme o ambiente onde se desenvolve ${ }^{1}$.

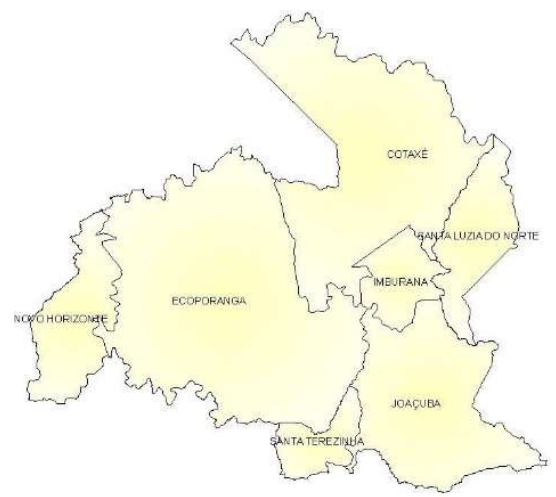

Mapa 1: Mapa do município/distritos - PROATER de 2011.

O Distrito é composto de grandes fazendas, pequenas propriedades rurais e assentamentos. É um distrito cortado pelo Córrego do Facão. Um córrego que se encontra assoreado devido à ação antrópica. Encontramos esgotos e muito lixo dentro do Rio. Ao redor do Distrito temos lavouras e pastagens. Também encontramos áreas que já são inservíveis para o cultivo devido a erosões e a as terras se tornarem

${ }^{1}$ https://incaper.es.gov.br/media/incaper/proater/municipios/Noroeste/Ecoporanga.pdf 
improdutivas. O Distrito vem enfrentando fortes secas nos últimos anos, sendo que em 2015 e 2016 os moradores foram abastecidos por caminhão pipa, pois não havia vazão para a captação de água do Rio.

\section{Caracterização da escola onde foi realizada a pesquisa de campo}

A Escola Estadual de Ensino Fundamental e Médio 'José Teixeira Fialho', localizada no Distrito de Imburana, Ecoporanga-ES é composta por uma clientela oriunda dos Distritos: Imburana, Cotaxé e Muritiba. Também se encontra estudantes que vem de assentamentos e acampamentos do entorno dos Distritos. Atualmente está com 250 estudantes. Dentre estes tem 38 estudantes provenientes da Educação Especial. Os estudantes têm ligação direta com as atividades do campo como: agricultores, pequenos produtores rurais, vaqueiros, extração do granito.

\section{A degradação ambiental encontrada no entorno da EEEFM José Teixeira Fialho e a necessidade de mudanças de paradigmas socioculturais e socioambientais}

Sabendo da atual situação que encontra o meio ambiente, percebe-se a importância de trabalhar este conceito Acerca da Educação Ambiental, Lima (1984, citado por GUIMARÃES, 1995). Onde diz:

Na Carta de Belgrado estão explicitados as metas e os objetivos da Educação Ambiental, onde o princípio básico é a atenção com o meio natural e artificial, considerando os fatores ecológicos, políticos, sociais, culturais e estéticos. Determina também que a educação deve ser contínua, multidisciplinar, integrada dentro das diferenças regionais, voltada para os interesses nacionais centrada no questionamento sobre o tipo de desenvolvimento. Tem como meta prioritária a formação nos indivíduos de uma consciência coletiva, capaz de discernir a importância ambiental na preservação da espécie humana e, sobretudo estimular um comportamento cooperativo nos diferentes níveis das relações inter e intranacionais.

(...) a educação ambiental assume a posição de promover conhecimento dos problemas ligados ao ambiente, vinculando - os a uma visão global; preconiza, também, a ação permanente, através da qual a comunidade toma consciência de sua realidade global, do tipo de relações que os homens mantêm entre si e com a natureza, dos problemas derivados destas relações e de suas causas profundas.

Seguindo este mesmo raciocínio Gonsalves (1984, citado por GUIMARÃES, 1995), onde nos orienta:

Provavelmente através do processo educativo, feito de Forma ativa, e da escola aberta e participativa, as atividades desenvolvidas em relação ao meio ambiente permitirão a abstração de valores muito mais duradouros do que os que têm conseguido a escola dita tradicional.

De acordo com Guimarães (1995):

Em EA é preciso que o educador trabalhe intensamente a integração entre ser humano e ambiente e se conscientize de que o ser humano é natureza e não apenas parte dela. Ao assimilar esta visão (holística), a noção de dominação do ser humano sobre o meio ambiente perde seu valor, já que estando integrado em uma unidade (ser humano /natureza) inexiste a dominação de alguma coisa sobre a outra, pois já não há mais separação. Podendo assim resultar em atitudes harmoniosas por parte do ser humano, em consonância com as relações naturalmente existentes entre os elementos vivos e elementos não-vivos de um ecossistema dinamicamente equilibrado.

As atividades econômicas realizadas na região como a extração do granito, agricultura e pecuária extensiva para criação de gado leiteiro e de corte tem levado ao desmatamento quase total das matas que 
existiam no entorno do Distrito. Hoje o que se encontra é pequenos fragmentos da Mata Atlântica em locais de difíceis acessos e que o homem ainda não teve como retirá-la.

Outro problema enfrentado é a ação humana que muitas vezes não leva em consideração que atitudes simples, ações cidadãs tornam o ambiente limpo e agradável. Encontra-se muito lixo doméstico e esgotos sendo despejados diretamente no Córrego que passa dentro do Distrito. As nascentes estão sem cobertura o que leva o Distrito a ser considerado o que se encontra em estado mais crítico em relação às secas.

Nos anos de 2015 e 2016, a população do Distrito foi abastecida com água potável por meio de caminhões pipa porque o nível de água baixou tanto que era impossível a captação para tratamento.

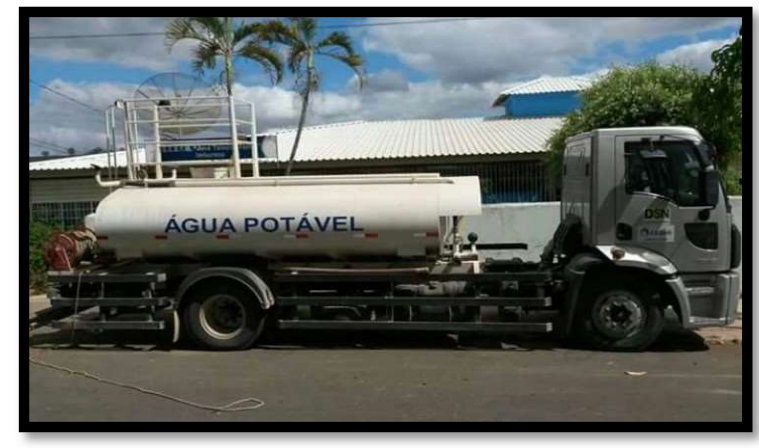

Imagem 1: Caminhão pipa em frente à escola para abastecimento com água potável.

Outro problema sério no Distrito é o uso de agroquímicos pela polução na pecuária e nas lavouras.

As terras carregadas pelas águas das chuvas levam para os rios, lagoas e barragens os resíduos de agrotóxicos, comprometendo a fauna e a flora aquática, além de comprometer as águas captadas com a finalidade de abastecimento. Podem também provocar o aumento das pragas ao invés de combatê-las, pois na medida em que se usam insumos químicos as pragas tornam-se mais resistentes, necessitando de agrotóxico cada vez mais forte, desse modo, agredindo ainda mais o ambiente e dizimando até os próprios predadores naturais das pragas.

E isso tem levantado preocupação no gestor escolar e toda comunidade do entorno. A escola não havia projetos de incentivo às práticas sustentáveis e de Educação Ambiental. E os resultados nas avaliações externas também estavam muito aquém do esperado. Levando a Instituição em 2014 a ser considerada uma das cem piores escolas do Brasil. Diante disso, foi feito ações voltadas para educação e gestão ambiental para que pudesse mudar a atual situação da escola. A equipe escolar sabe que 'o conhecimento não é dado nem adquirido, ele é mostrado, acentuado, demonstrado pelo professor e, a partir dessas operações, ele é construído pela criança' (FRIEDRICH, 2012). Não só pela Criança, mas, também pelo adolescente, pelos jovens e adultos. Pois todos, alunos, professores e comunidade aprendem muito com ações práticas no cotidiano escolar. A interação com o meio é uma ferramenta muito rica para produção de conhecimentos.

\section{A sustentabilidade como mola propulsora na gestão e educação ambiental}

Segundo Guimarães (1995) diz que:

Os seres humanos superam, e muito, os seus limites biológicos de intervenção no meio, atingindo duramente a capacidade suporte do ambiente. Isso deu-se principalmente a partir da Revolução Industrial, em que o ser humano conquista tecnologia cada vez mais 
poderosa. Tecnologia que traz intrinsecamente em sua concepção valores antropocêntricos, consumistas, fragmentados e por consequência destrutivos ambientalmente, em que a qualidade e a quantidade da intervenção dos seres humanos sobre a natureza por meio dessa tecnologia assumiram parâmetros atuais, com grandes e nefastos impactos ambientais.

A sustentabilidade deve ser a mola propulsora sempre que se expressa gestão e educação ambiental. Não podemos retirar da natureza mais do que ela pode nos oferecer. Além disso, é necessário de uma ação consciente em relação ao uso dos recursos naturais para a preservação e a perpetuação de um ambiente harmonioso para as futuras gerações. É necessário um pensar coletivo, sobre fatores bióticos e abióticos para que entendamos dessa relação de interdependência, onde precisa existir um respeito para com o ambiente e tudo que nele existe.

O enfoque centrado no ser humano como ser superior que vive no planeta, sendo o ator principal na história planetária, levando apenas suas concepções capitalistas e egocêntricas precisa ser reavaliado. A educação ambiental centra o enfoque no equilíbrio dinâmico do ambiente, em que a vida é percebida em seu sentido pleno de interdependência de todos os elementos da natureza. Os seres humanos e demais seres então em parcerias que perpetuam a vida. Precisa-se apreender que a vida de cada ser não é absoluta. Porque no sentido pleno da vida, a morte está incluída e presente no equilíbrio dinâmico do ambiente. A mudança desse enfoque é que tem gerado as diversas transformações e os atuais desequilíbrios ambientais.

\section{Práticas de educação ambiental e a aplicação do currículo}

No Currículo do Estado do Espírito Santo, SEDU de 2009, na p.41 e 42, no item 3.4 encontra-se a importância da Educação Ambiental. Veja a seguir o que nos apresenta este item:

A Educação Ambiental é um tema transversal a ser trabalhado em todos os níveis e modalidades de ensino na educação básica. Constitui - se em um processo permanente, fundamentado no respeito a todas as formas de vida, no reconhecimento da complexidade socioambiental e em valores e ações que contribuam para a (trans)formação. Ao invés de produzirmos alimentos, habitações e bens muito duráveis, são produzidos bombas e bens com duração muito reduzida. Os serviços deveriam ser realizados por equipamentos coletivos. Deveria ser estabelecida uma nova ética que rejeitasse a exploração, o consumismo e a exaltação da produção como fim por si só. Será necessária uma nova forma de agricultura e de indústria, uma nova urbanização, e um novo urbanismo e uma nova forma de produção e consumo com largos benefícios que terão de lidar com a complexidade da realidade. A educação para o ambiente deve formular constantemente seus métodos, conteúdos. Constitui - se em um processo permanente, fundamentado no respeito da complexidade socioambiental e em valores e ações que contribuam para a (trans) formação do ser humano. Seu ideário é as formações de sociedades que são, ao mesmo tempo, ecologicamente prudentes, economicamente viáveis, socialmente justas, culturalmente diversas e politicamente atuantes. A promoção da Educação Ambiental em todos os níveis e modalidades de ensino está estabelecida na Lei 9795/99 e contribuirá para a formação humana, se colocada nos princípios da solidariedade, da cooperação, da democracia, da justiça social e ambiental, se promover a emancipação dos sujeitos para uma participação social efetiva, com respeito à alteridade e à diversidade social, ética e cultural dos povos. 0 adjetivo ambiental na educação nos dá a ilusão de que se a Educação Ambiental for desenvolvida nas escolas, valores e atitudes em relação ao meio ambiente serão transformados qualitativamente. Ainda que a Educação Ambiental esteja ratificada no currículo por meio do aparato legal, é preciso situá - La historicamente e explicitar as contradições e as causas do antagonismo cultivado entre ser humano e natureza. A educação ambiental ainda vem acontecendo nas escolas de forma episódica, eventual e de modo paralelo ao desenvolvimento curricular. Para que a Educação Ambiental torne - se 
efetiva nas escolas é necessária uma mudança de valores e postura de toda a comunidade, no envolvimento com os problemas e as questões socioambientais em termos locais e globais. Além de incluir a temática no projeto político pedagógico da escola, é preciso que a Educação Ambiental seja vista como parte de um plano coletivo da comunidade escolar. A educação ambiental pressupõe a implementação de metodologias participativas, cooperativas, interdisciplinares, que se definem no compromisso de qualificar a relação com o meio ambiente, considerando a complexidade e a multidimensionalidade da questão ambiental no exercício da participação social e a defesa da cidadania como práticas indispensáveis à democracia e à emancipação socioambiental.

As Diretrizes Curriculares Nacionais da Educação Básica (BRASIL, 1996) afirmam que:

Uma escola que inclui todos supõe tratar o conhecimento como processo e, portanto, como uma vivência que não se harmoniza com a ideia de interrupção, mas sim de construção, em que o estudante, enquanto sujeito da ação, está continuamente sendo formado, ou melhor, formando-se, construindo significados, a partir das relações dos homens entre si e destes com a natureza.

A escola quando trabalha a educação ambiental não pode ficar trancada dentro de seus muros. Mas permitir uma participação multiprofissional. E buscar parcerias interdisciplinares, transdisciplinares, já que esse é um tema que transpassa qualquer disciplina e que se encaixa em cada ação praticada por cada ser humano frente às causas e consequências vivenciadas e criadas pelas ações antrópicas. Com essa visão abrangente, pode-se dizer que o trabalho poderá ter os objetivos alcançados.

O trabalho de conscientização deve ser mantido como uma teia, formada por vários fios. Cada fio dando sua contribuição sem querer ser maior ou melhor que o outro, mas defendendo sua posição e seu espaço. Assim deve ser cada membro que compõe uma sociedade cidadã. Cada ser vivo fazendo sua parte, para que todos sejam beneficiados.

\section{A necessidade de o gestor apoiar as ações transdisciplinares sobre educação ambiental nas escolas}

Percebe-se muito apoio das equipes gestoras o apoio a eventos culturais e pouco incentivos às práticas experimentais. Geralmente as equipes pedagógicas valorizam muito ações que envolvam a cultura, mas urge a necessidade de equilíbrio entre os campos para a formação plena do cidadão na perspectiva de uma educação integral: Campo sociocultural, socioemocional, socioeconômico e socioambiental.

Devem-se valorizar as produções artísticas e as produções realizadas pelos estudantes; o ser humano para uma aprendizagem plena precisa contar com um ambiente que colabore para sua segurança e ao protagonismo, deve-se levar o estudante a pensar sobre a produção de bens e consumo e como podemos equilibrar essas ações, e precisa-se de uma nova visão sobre a postura adotada quanto ao meio ambiente. Tem que relacionar a Ciência a Tecnologia e a sociedade para produção de forma consciente.

Segundo Guimarães (1995):

Conforme os princípios básicos descritos pela Educação Ambiental, o planejamento das ações deve ser essencialmente participativo: professores, alunos segmentos comunitários, agentes sociais de uma prática social em que cada contribua com sua experiência acumulada, sua visão de mundo e suas expectativas, aflorando condições. Dessa forma, facilita a compreensão e a atuação integral e integrada sobre a realidade vivenciada. As pessoas envolvidas nesse processo terão, como um exercício de cidadania, uma participação ativa na elaboração teórica e prática das ações para a superação dos problemas diagnosticados. Simultaneamente, essas ações estarão comprometidas com a realidade ambiental do local em que se vivencie esse processo. 
Na EEEFM José Teixeira Fialho, ações culturais são muito respeitadas, mas, temos também ações de responsabilidade social voltadas para melhorias frente aos problemas socioambientais enfrentados. $\mathrm{Na}$ escola é desenvolvido diversos projetos e todos são apoiados pela direção e supervisão escolar, dando o suporte nece3ssário e buscando parcerias para o desenvolvimento de uma prática educativa de acordo com a Legislação vigente com um foco todo especial na Sustentabilidade.

As práticas educativas sobre ciência, Tecnologia, Sociedade e Ambiente desenvolvidas na escola tem ganhado repercussão em todo o Estado. Com vários projetos de ensino sendo reconhecidos e premiados.

\section{A educação ambiental aplicada ao cotidiano escolar}

O cotidiano escolar é muito rico para se trabalhar a educação ambiental. É ali, onde estudantes passam boa parte de seu dia convivendo com pessoas diferentes e com pensamentos diferentes e que se unem em busca de um só objetivo: A aprendizagem. E diante disso, pode-se utilizar desse meio para o entendimento da Educação Ambiental. Cunha (1999) define os princípios básicos do pragmatismo como,

[...] o pensamento e a ação devem formar um todo indivisível, o que implica tratar qualquer formulação teórica como hipótese ativa que carece de demonstração em situação prática de vida; as constantes transformações sociais fazem com que a realidade não constitua um sistema acabado e imutável; a inteligência garante ao homem a capacidade de alterar as condições de sua própria experiência. Para os pragmatistas, o terreno em que se dá a transmissão do conhecimento, particularmente a escola, pode tornar-se um campo fértil de experimentação de teses filosóficas.

Na escola, hipóteses são testadas, confirmadas ou refutadas. Nesse contexto, em 2015, estudantes ainda sentavam sobre as mesas do refeitório; iam ao sanitário e deixavam torneiras abertas, os bebedouros estavam velhos e as torneiras desperdiçando água, as mesas eram rabiscadas e sujas. Os estudantes e professores encontravam-se muito desmotivados frente aos resultados obtidos em avaliações externas em anos anteriores. Foi feito nessa Instituição um trabalho de resgate de valores e respeito coletivo. Mudanças aconteceram em todos os setores. Os estudantes e profissionais da instituição mudaram dentro de um curto período de tempo e aos poucos voltaram a sentir o senso de pertencimento à Instituição. Hoje tem orgulho de estudarem na Escola.

Para Hernández et al. (1998),

A função do projeto é favorecer a criação de estratégias de organização dos conhecimentos escolares em relação a: 1) o tratamento da informação; e 2) a relação entre os diferentes conteúdos em torno de problemas ou hipóteses que facilitem aos alunos a construção de seus conhecimentos, a transformação da informação procedente dos diferentes saberes disciplinares tem conhecimento próprio.

Para Hernández et al. (1998), o trabalho com projetos,

Aproxima-se da identidade dos alunos e favorecer a construção da subjetividade, longe de um prisma paternalista, gerencial ou psicologista, o que implica considerar que a função da escola não e apenas ensinar conteúdos, nem vincular a instrução com a aprendizagem. Revisar a organização do currículo por disciplinas e a maneira de situá-lo no tempo e nos espaços escolares. O que torna necessária a proposta de um currículo que não seja uma representação do conhecimento fragmentada, distanciada dos problemas que os alunos vivem e necessitam responder em suas vidas, mas, sim, solução de continuidade. Levar em conta o que acontece fora da escola, nas transformações sociais e nos saberes, a enorme produção de informação que caracteriza a sociedade atual, e aprender a dialogar de uma maneira crítica com todos esses fenômenos. 
Para Hernández et al. (1998) a pesquisa apresenta um papel de suma importância no ensino porque,

A finalidade do ensino é promover, nos alunos, a compreensão dos problemas que investigam. Compreender é ser capaz de ir além da informação dada, é poder reconhecer as diferentes versões de um fato e buscar explicá-las além de propor hipótese sobre as consequências dessa pluralidade de pontos de vista.

Diante disso, sendo uma proposta essencialmente comunitária, materializa-se através de uma prática cujo objetivo maior é a promoção de uma aprendizagem que respeite o meio ambiente, e que busque em suas ações a proteção ambiental. Demonstra uma concepção determinada, porquanto pressupõe ações voltadas para o surgimento de novos valores, onde a participação coletiva é um princípio fundamental.

Deve-se buscar uma prática pedagógica onde o ser humano seja mais livre para expor suas ideias, e reflexivamente descobrir-se e conquistar-se como sujeito de sua própria destinação histórica. A Educação Libertadora, enquanto processo de formador de agentes de transformação da ética da população quanto ao desenvolvimento de novas atitudes, ao trato com o meio ambiente, constituindo de fato a Educação Ambiental.

\section{Projetos transdisciplinares e práticas de educação ambiental por meio de aplicação de projetos de ensino na EEEFM José Teixeira Fialho}

De acordo com os estudos realizados por área de conhecimento, baseando-se nas explanações de Antoni Zabala, a escola vem trabalhando com sequências didáticas, que valorizem uma atenção à diversidade encontrada no contexto escolar, construindo planos de aula que valorizem uma abordagem dos conteúdos conceituais, procedimentais e atitudinais. A aprendizagem dos conteúdos de acordo com suas tipologias vem gerando bons resultados. Diante do exposto acima, podemos dizer que: Não basta fazer, é preciso saber fazer. E na educação procura-se essa constante transformação.

Segundo Gardner (1995): “Os seres humanos são considerados, por excelência, as criaturas da comunicação, que armazenam significados através de palavras, desenhos, gestos, números, padrões musicais e um grande número de outras formas simbólicas".

Na EEEFM 'José Teixeira Fialho', procura-se trabalhar teoria e prática de forma muito intrínseca. E com isso conseguiu-se um saldo muito positivo através das ações e projetos voltados para Ciência, tecnologia, sociedade e ambiente (CTSA), de acordo com os temas abordados na Semana Nacional de Ciência e Tecnologia, obtendo em 2015 no evento da Semana Estadual de Ciência e tecnologia, com o tema: 'Luz, Ciência e Vida' o 2 o lugar, com um projeto sobre a reciclagem do alumínio. Os estudantes juntavam o alumínio e um dos profissionais da escola transformava os restos de alumínio em utensílios domésticos.

Em 2016, durante a Semana Estadual de Ciência e tecnologia, com o tema: 'Ciência alimentando o Brasil' a escola ficou em 3 o lugar, com um projeto onde os estudantes juntamente com os professores estudaram sobre a planta nim, extraindo o extrato conseguiram obter um pesticida natural evitando assim o uso de agroquímicos. 
Em 2017, durante a Semana Nacional de Ciência e Tecnologia, com o tema: 'A Matemática está em tudo', a escola foi a única Instituição pública a ser homenageada pelo Governo do Estado por meio do Conselho Estadual de Ciência e Tecnologia - CONCITEC, na categoria Instituição Pública.

Em 2018, a escola foi finalista na V Conferência Infanto-juvenil pelo Meio Ambiente com o tema: 'Vamos Cuidar do Brasil cuidando das águas'. O projeto foi sobre a recuperação da nascente do Córrego do facão. Córrego esse que passa dentro do Distrito. Essa ação fez com que os estudantes mudassem de comportamento frente ao lixo dentro do Córrego. O projeto teve tanta repercussão que o prefeito enviou uma equipe para fazer a limpeza do Córrego. O projeto 'Percepção ambiental e recuperação da nascente do Córrego Facão do Distrito de Imburana, Ecoporanga-ES', apresentado pela estudante delegada, acompanhada pela professora orientadora e o diretor. A estudante teve a oportunidade de ir para o Estado de São Paulo, na cidade de Sumaré, onde a estudante e o diretor visitaram os estandes e observaram os trabalhos que foram finalistas de todos os Estados do Brasil. E também tiveram a oportunidade de conviver com pessoas de outros Estados e analisar a riqueza cultural que tem no Brasil.

A Conferência Nacional Infanto-juvenil pelo Meio Ambiente é o encontro das delegações estaduais para realização de oficinas, atividades culturais e diálogos sobre o tema 'Água', a partir dos projetos de ação selecionados nas etapas Estaduais e Distritais. Tem como objetivo fortalecer a educação ambiental nos sistemas de ensino, propiciando atitude responsável e comprometida da comunidade escolar com as questões socioambientais locais e globais com ênfase na participação social e no ensino-aprendizagem.

Em 2019, a Escola participou da I Feira de Ciência Norte Capixaba - FECINC - com os seguintes projetos: 1 - Coleta seletiva e reciclagem como instrumentos de aprendizagem nas disciplinas da área de ciência da natureza e matemática com enfoque sustentável; 2 - Percepção ambiental e Recuperação da Nascente do Córrego Facão do Distrito de Imburana, município de Ecoporanga-ES; 3 - Levantamento etnobotânico e Preservação do uso de Plantas Medicinais do município de Ecoporanga-ES; 4 - A arte representa a vida: Releitura das obras de Sebastião Salgado com abordagem conservacionista; 5 - Calcular + Cozinhar $=$ A Arte de Reaproveitar.

O projeto Levantamento Etnobotânico e Preservação do Uso de Plantas Medicinais do município de Ecoporanga, orientado pela professora Ivani Vieira Damaceno conquistou a terceira colocação como melhor projeto na área de ciências biológicas.

O projeto intitulado CALCULAR MAIS COZINHAR IGUAL A ARTE DE REAPROVEITAR, realizado pelos estudantes e sob orientação e coorientação de professores da área de ciências da natureza. Foi apresentado durante a Feira de Ciências Norte Capixaba - Fecinc 2019, que aconteceu nos dias 30 e 31 de maio de 2019 no ginásio poliesportivo da UFES - em São Mateus, ES. Ao final da feira, o projeto CALCULAR MAIS COZINHAR IGUAL A ARTE DE REAPROVEITAR recebeu as seguintes premiações: Credenciamento para Feira XIII Mostra CLAK; $3^{\circ}$ Colocado Geral; $1^{\circ}$ Colocado na área de Ciências Biológicas; Destaque da cidade de Ecoporanga /ES. A XIII Mostra CLAK é um evento científico nacional que acontece no Colégio Luterano Arthur Konrath, em Estância Velha-RS. As estudantes por meio do protagonismo estão angariando recursos para participarem do evento. Um mesmo projeto receber quatro premiações é sinal que todos os esforços realizados para 
superação dos limites e barreiras impostas por intempéries climáticas e os diversos problemas enfrentados para estudar em uma região do interior, não significa que existe estudantes estagnados e que não tem perspectivas de futuro, mas pelo contrário, estão demonstrando que os (as) estudantes dos Distritos têm muito a contribuir para melhorias dos índices da escola, da SRE e do Estado.

A Unidade de Ensino também participou esse ano da Olimpíada Brasileira de Astronomia e da Mostra Brasileira de Foguetes 13a Mostra Brasileira de Foguetes (13a MOBFOG). A equipe da escola que teve o mais longínquo lançamento de foguetes da Mostra Brasileira de Foguetes recebeu como prêmio o convite para participar das JORNADAS DE FOGUETES na cidade de Barra do Piraí, RJ, organizadas pela Mostra Brasileira de Foguetes, MOBFOG, em parceria com a Olimpíada Brasileira de Astronomia e Astronáutica, OBA.

Tivemos também como destaque esse ano uma estudante do Ensino Médio que participou da 6a edição da Feira Literária Capixaba (Flic-ES), sendo esse o maior evento literário do Espírito Santo. O poema da estudante ficou classificado entre os 50 melhores poemas do Estado em uma seleção com mais de 200 poemas e será publicado em uma antologia.

\section{Resultados de aprendizagem obtidos na EEEFM José Teixeira Fialho a Partir dos Projetos de Ensino sobre Gestão e Sustentabilidade}

Uma Instituição contendo Ensino Fundamental I, Ensino Fundamental II e Ensino Médio, com mais ou menos duzentos e trinta estudantes, compostos de classe média e classe média baixa, advindos de três Distritos: Cotaxé, Muritiba e Imburana e assentamentos. Estudantes que até então não viam perspectivas de vida e nem tinham um projeto de vida. E que agora estão trazendo todos esses resultados para essa Instituição, demonstra que paradigmas foram mudados e que novos rumos a educação vêm tomando dentro da perspectiva de uma educação integral, com práticas inclusivas e que buscam melhores resultados de aprendizagens.

A escola tem melhorado em todos os aspectos. Em relação aos espaços físicos, temos uma quadra recém-inaugurada e que serve para diversos eventos da escola. Em relação às salas de aula, todas foram climatizadas, por meio do Programa Ensino Médio Inovador com a aquisição de aparelhos de ar condicionados. Os professores estão buscando continuamente formação continuada. E isso também impacta de forma positiva nos resultados da escola.

Para os próximos anos, a equipe escolar vem se apropriando das tecnologias digitais e comunicação na educação, inscrições nas Olimpíadas de foguetes, Olimpíada Brasileira de Astronomia, Olimpíada Brasileira de Matemática, Olimpíada Brasileira de Ciências, projetos científicos com pesquisa de campo, utilização de máquinas e equipamentos que melhorem o processo ensino - aprendizagem, climatização dos ambientes escolares e essas ações e Práticas Pedagógicas Inovadoras vem gerando bons frutos na evolução do processo educacional da Instituição.

Diante dos relatos supracitados e os índices que serão apresentados nos quadros totalizadores de cada ano percebe-se o quanto a escola está evoluindo. Sabemos que nossos estudantes precisam de oportunidades. E essas oportunidades são produzidas obtendo uma educação de qualidade. $O$ trabalho 
realizado na Instituição tem resgatado estudantes que estavam desmotivados. A escola quase não existe mais estudantes que se evadem durante o ano, a comunidade abraçou a escola e acredita no trabalho de qualidade que é desenvolvido. A comunidade escolar, entendeu de fato a palavra corresponsabilização.

Sendo educadores, professores por mérito e honra, podemos constatar que passamos por muitas situações adversas na educação, cientes que não temos uma fórmula mágica para resolver todos os problemas, pois temos fatores internos e externos que precisam ser enfrentados no cotidiano escolar. Entretanto, podemos unir como ilhas e formar grandes continentes. Unindo forças e buscando soluções indo sempre avante. Uma das piores escolas hoje está entre uma das melhores escolas da região. Graças a um trabalho sério. Comprometido e de qualidade. Mas tudo foi possível, graças ao trabalho diferenciado e a nova visão que o Programa Jovem de Futuro nos proporcionou. $\mathrm{O}$ trabalho em equipe fez a diferença durante todo o processo.

Tabela 1: Indicadores de produtividade Institucional.

\begin{tabular}{|l|l|l|l|l|l|l|}
\hline & Matrículas & Aprovação & Reprovação & Evasão & Transferência & Aproveitamento Total \% \\
\hline 2014 & 255 & 201 & 54 & 18 & 24 & $78,8 \%$ \\
\hline 2015 & 235 & 202 & 33 & 15 & 24 & $85,9 \%$ \\
\hline 2016 & 212 & 187 & 25 & 3 & 46 & $88,2 \%$ \\
\hline 2017 & 206 & 203 & 3 & 0 & 21 & $98,5 \%$ \\
\hline 2018 & 197 & 188 & 09 & 2 & 49 & $95,43 \%$ \\
\hline
\end{tabular}

\section{CONCLUSÕES}

A educação ambiental apresenta uma nova dimensão a ser incorporada ao processo educacional. Sendo um tema gerador de discussões e controvérsias. Mas que ao longo dos anos foi esquecido com a fragmentação do saber, representado pelas especializações do conhecimento, que aprofundou a compreensão por áreas.

Para o desenvolvimento desta pesquisa, além do uso de vários livros de autores renomados sobre a Educação Ambiental, foi realizada uma pesquisa de campo sobre a atuação dos professores em sala de aula sobre o assunto abordado na pesquisa. Foi elaborado um questionário para ser respondido pelos professores acerca da EA e sua abordagem. Todos responderam propondo a importância do trabalho em grupo, integrando as diversas áreas de conhecimento. Falaram também sobre a importância de inserir a EA no Projeto Político Pedagógico da Escola. Mas infelizmente a maneira como aplicam a EA em suas aulas são quase sempre, teórica, que de acordo com Guimarães (1995) não traz grandes resultados.

Mas infelizmente com tantos estudos realizados todos os professores que responderam ao questionário, concordaram com a criação da disciplina da EA, fato que se for realizado será mais uma disciplina sem alcançar os objetivos. Pois Educação Ambiental é um tema a ser abordado por todos, pois é um tema complexo e que depende de vários segmentos comunitários para sua plena execução.

O ambiente é uma unidade que precisa ser compreendida por inteiro. E somente poderá ser desvendada e estudada através de um conhecimento interdisciplinar, onde poderemos assimilar plenamente o equilíbrio dinâmico do ambiente. 
É através da educação ambiental que nós compreendemos a importância da integração existente entre os fatores bióticos e abióticos do ambiente. E que este equilíbrio dinâmico da natureza às vezes vem sendo fragmentado pelo homem moderno.

Por ser um tema global a educação ambiental deve ser trabalhada em equipe. Ou seja, sempre com uma ação participativa. Pois é um tema social. E de interesse de todos os seres humanos. Porque é neste ambiente que é possível existir vida.

A educação ambiental é uma temática que deve ser incluída no projeto político pedagógico da escola. E que todos da comunidade escolar deve ajudar a desenvolver. Além disso, a escola quando ao trabalhar a educação ambiental deve buscar parcerias com outras entidades para que o seu trabalho possa surgir efeito.

Além da parte teórica não podemos esquecer que educação ambiental sem prática não existe. Porque todos nós sabemos dos problemas existentes no meio ambiente. Por isso temos que aplicar educação ambiental teórica e prática, para que possamos ver o surgimento de um mundo ético, de qualidade, com práticas cidadãs indispensáveis à democracia e à emancipação socioambiental, protegendo a biodiversidade de nosso planeta.

Através deste trabalho podemos compreender o quanto é importante trabalhar na prática e saímos da teoria. Aliás, o que adianta se tivermos a parte teórica, mas nunca a usarmos? Por isso temos que preocupar com a parte teórica, mas nuca deixarmos de trabalhar está temática na prática.

\section{REFERÊNCIAS}

BRASIL. Ministério da Educação e do Desporto. Secretaria de Educação Fundamental. Lei n. 9.394, de 20 de dezembro de 1996. Estabelece as diretrizes e bases da educação nacional. Brasília: MEC/SEF, 1996.

CUNHA, M. V.. John Dewey: uma filosofia para educadores em sala de aula. 3 ed. Petrópolis: Vozes, 1999.

FRIEDRICH, J. L. V.. Mediação, aprendizagem e desenvolvimento: uma leitura filosófica e epistemológica. São Paulo: Mercado de Letras, 2012.
GARDNER, H.. Inteligências múltiplas: a teoria na prática. Porto Alegre: Artes Médicas, 1995.

GUIMARÃES, M.. A dimensão ambiental na educação. 2 ed. Campinas: Papirus, 1995.

HERNÁNDEZ, F.; VENTURA, M.. A organização do currículo por projetos de trabalho: o conhecimento é um caleidoscópio. Porto Alegre: ArtMed, 1998.

A CBPC - Companhia Brasileira de Produção Científica (CNPJ: 11.221.422/0001-03) detém os direitos materiais desta publicação. Os direitos referem-se à publicação do trabalho em qualquer parte do mundo, incluindo os direitos às renovações, expansões e disseminações da contribuição, bem como outros direitos subsidiários. Todos os trabalhos publicados eletronicamente poderão posteriormente ser publicados em coletâneas impressas sob coordenação da Sustenere Publishing, da Companhia Brasileira de Produção Científica e seus parceiros autorizados. Os (as) autores (as) preservam os direitos autorais, mas não têm permissão para a publicação da contribuição em outro meio, impresso ou digital, em português ou em tradução. 